\title{
TINGKAT KEMATANGAN TATA KELOLA TEKNOLOGI INFORMASI MENGGUNAKAN METODE TESCA PADA PERGURUAN TINGGI
}

\author{
${ }^{1}$ Hery Mustofa, ${ }^{2}$ Syaiful Bakhri \\ 1,2Universitas Islam Negeri Walisongo Semarang, Indonesia \\ Iherymustofa@walisongo.ac.id, ${ }^{2}$ syaifulbakhri@walisongo.ac.id
}

\begin{tabular}{l} 
Article Info \\
\hline Article history: \\
Received, 23/11/2020 \\
Revised, 25/11/2020 \\
Accepted, 26/11/2020 \\
\hline Kata Kunci: \\
Tesca \\
Audit_ti \\
Tatakelola \\
\hline
\end{tabular}

\begin{abstract}
ABSTRAK
Evaluasi tata kelola TIK menjadi bagian penting dalam penerapan TIK dalam sebuah perguruan tinggi. Tata kelola teknologi informasi yang baik akan membantu mempercepat terwujudnya visi dan misi sebuah perguruan tinggi. Pusat Teknologi Informasi dan Pangkalan Data (PTIPD) UIN Walisongo merupakan unit teknis yang mempunyai tugas mengelola dan mengembangkan sistem informasi di lingkungan Institusi. Mengingat pentingnya PTIPD maka perlu dilakukan evaluasi tingkat kematangan teknologi informasi dengan menggunakan metode TeSCA. Analisis dilakukan dengan teknik observasi, wawancara, penelaah dokumen dan konfirmasi untuk mendukung analisis terhadap PTIPD. Hasil analisis menunjukkan bahwa tingkat kematangan TIK UIN Walisongo pada tingkat Level Madya dengan scores total 55.43 .
\end{abstract}

\begin{abstract}
Evaluation of ICT governance is an important part of the application of ICT in a university. Good information technology governance will help accelerate the realization of the vision and mission of a university. The Center for Information Technology and Data Base (PTIPD) UIN Walisongo is a technical unit that has the task of managing and developing information systems within the Institution. Given the importance of PTIPD, it is necessary to evaluate the maturity level of information technology using the TeSCA method. The analysis was carried out by means of observation, interview, document review and confirmation techniques to support the analysis of PTIPD. The results of the analysis show that the ICT maturity level of UIN Walisongo is at the Intermediate Level level with a total score of 55.43.
\end{abstract}

Keywords:

Tesca

Audit_ti

governance

This is an open access article under the CC BY-SAlicense.

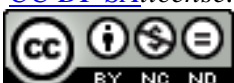

\section{PENDAHULUAN}

Penerapan teknologi informasi untuk mendukung proses bisnis organisasi dalam mencapai visi misi merupakan kebutuhan yang sangat penting. [1] Teknologi informasi menjadi peran penting [2] dalam proses bisnis perguruan tinggi. Peningkatan mutu akademik melalui pemanfaatan teknologi informasi selaras dengan perkembangan teknologi. [3] Saat ini, penggunaan teknologi informasi tidak bisa dilepaskan dari perguruan perguruan tinggi. Teknologi bukan sekedar sarana prasarana yang mendukung kegiatan yang ada di perguruan tinggi, tapi teknologi informasi menjadi penggerak proses bisnis dalam perguruan tinggi.

Dengan menerapkan teknologi informasi, perguruan tinggi akan sangat cepat dan mudah dalam meningkatkan pelayanan kepada stakeholder perguruan tinggi tersebut. Perguruan tinggi di Indonesia sudah menggunakan teknologi informasi sebagai pendukung pengajaran, penelitian dan pengabdian. Sekitar 20\% perguruan tinggi yang telah memanfaatkan sistem teknologi informasi dan komunikasi dalam kegiatan pendidikannya. [4] 
Pemanfaatan teknologi informasi dalam dunia pendidikan telah dilakukan di segala bidang. Teknologi informasi menjadi tulang punggung semua kegiatan bisnis pendidikan. Dimulai dari proses pendaftaran mahasiswa, proses belajar mahasiswa sampai dengan proses administrasi mahasiswa. Dengan pemanfaat teknologi informasi akan memudahkan pengelola pendidikan dalam melakukan manajemen pekerjaan. Infratruktur teknologi informasi sudah menjadi kebutuhan yang mendasar dalam mendukung efektifitas dan kualitas proses pendidikan. Isu-isu pendidikan di Indonesia seperti kualitas dan relevansi pendidikan, akses dan ekuitas pendidikan, rentang geografi, manajemen pendidikan, otonomi dan akuntabilitas pendidikan, efisiensi dan produktivitas pendidikan, anggaran dan sustainabilitas pendidikan, tidak akan terselesaikan dengan cepat tanpa bantuan teknologi informasi. [5]

Tata kelola sistem teknologi informasi dan komunikasi yang dibutuhkan untuk pendidikan tinggi yaitu agar tercipta proses penyebaran ilmu dalam kegiatan pembelajaran yang lebih interaktif dan dinamis, tata kelola operasional yang baik, serta peningkatan kinerja berbasis evaluasi dengan penilaian yang transparan, serta keamanan data dan informasi yang berhubungan dengan hak intelektual seseorang. [4] Untuk mencapai good governance perlu panduaan bagi institusi pemerintahan dan entitas pengambil keputusan didalamnya dalam pengelolaan sumber daya TIK agar manfaat dalam perspektif nasional, institusional dan publik akan mengalami peningkatan secara signifikan. [6]

Tata Kelola Teknologi informasi (TI Governance) telah banyak diimplementasikan oleh berbagai Institusi Perguruan Tinggi di berbagai dunia. Teknologi informasi (TI Governance) berperan penting dalam mendukung pencapaian misi, visi, tujuan Perguruan Tinggi tersebut dalam beradaptasi perubahan teknologi baru, inovasi dan perubahan lingkungan dalam meminimalisasi resiko dan mengatasi kerentanan keamanan Teknologi Informasi. [7] IT Govenance memastikan pengukuran efektifitas dan efisiensi peningkatan proses bis perusahaan. [8] Saat ini telah cukup banyak perguruan tinggi di tanah air yang mengadopsi pemanfaatan TIK dengan berbagai strategi, kapabilitas, dan fiturnya. Negara pun telah cukup banyak membantu mereka, khususnya perguruan tinggi negeri, dalam hal pemberian bantuan hibah berbagai fas ilitas dan sarana prasarana terkait dengan TIK, seperti pengadaan komputer, penyewaan bandwith , penyediaan jejaring, pengembangan konten, dan lain sebagainya [9]

Pengukuran atau evaluasi atas pemanfaatan teknologi infomasi dilakukan secara ilmiah harus dilakukan dalam perguruan tinggi, untuk mengtahui sejauh mana keberhasilan atau kelemahan pemanfaatan teknologi informasi. Pada kenyataannya pelaksanaan tatakelola TI tidak selalu berjalan lancar. [10] Evaluasi adalah suatu rangkaian kegiatan dalam mengumpulkan informasi tentang babagai suatu proses yang terjadi, informasi yang telah dikumpulkan tersebut digunakan untuk menentukan pilihan dan saran untuk mengambil keputusan. Berhasil atau tidaknya dan ada atau tidak adanya manfaat dari sebuah program kebijakan dapat juga dilakukan sebuah proses yang namanya evaluasi. Evaluasi dapat diartikan juga sebagai proses memberikan nilai terhadap dampak dari suatu program, objek atau sebuah rangkaian proses dengan rangkaian dan persyaratan yang telah ditentukan sebelumnya. [11]

Pengukuran tingkat kematangan tata kelola teknologi informasi akan sangat berguna bagi Perguruan tinggi dalam menentukan arah kebijakan strategis kedepan. UIN walisongo merupakan perguruan tinggi yang mempunyai viai Universitas Islam Riset Terdepan Berbasis pada Kesatuan Ilmu Pengetahuan untuk Kemanusiaan dan Peradaban pada Tahun 2038. [12] Dalam mewujudkan visi tersebut harus mempunyai tatak kelola teknologi informasi yang handal. Oleh karena itu, dalam penelitian ini akan dilakukan pengukuran tata kelola TIK di perguruan tinggi khusunya di UIN Walisongo menggunakan TesCa.

TEsCA adalah merupakan sebuah framework tata kelola teknologi informasi yang sebagai sebuah standar framework dalam pemanfaatan sebuah teknologi informasi di sebuah Institusi/organisisi. Dan digunakan untuk mengendalikan tata kelola TI. [7]. TeSCA sebuah program self assessment untuk mengukur pemanfaatan Teknologi Informasi \& Komunikasi perguruan tinggi di Indonesia dengan mengadopsi metode "ZACHMAN Framework". TesCA di Sponsori dan didukung oleh APTIKOM, KEMENDINAS, Dewan TIK Nasional, KOMINFO, Tim Riset Warta Ekonomi dan Telkom. 
JSAI : Journal Scientific and Applied Informatics

Vol. 3, No. 3, November 2020, hal. 122-128

E-ISSN: 2614-3054; P-ISSN: 2614-3062, accredited by Kemenristekdikti, Sinta 5

DOI: 10.36085

\section{METODE PENELITIAN}

Metode penelitian pada dasarnya merupakan cara ilmiah untuk mendapatkan data dengan tujuan dan kegunaan tertentu. [13] Metode penelitian dilakukan dengan tahapan seperti gambar berikut :

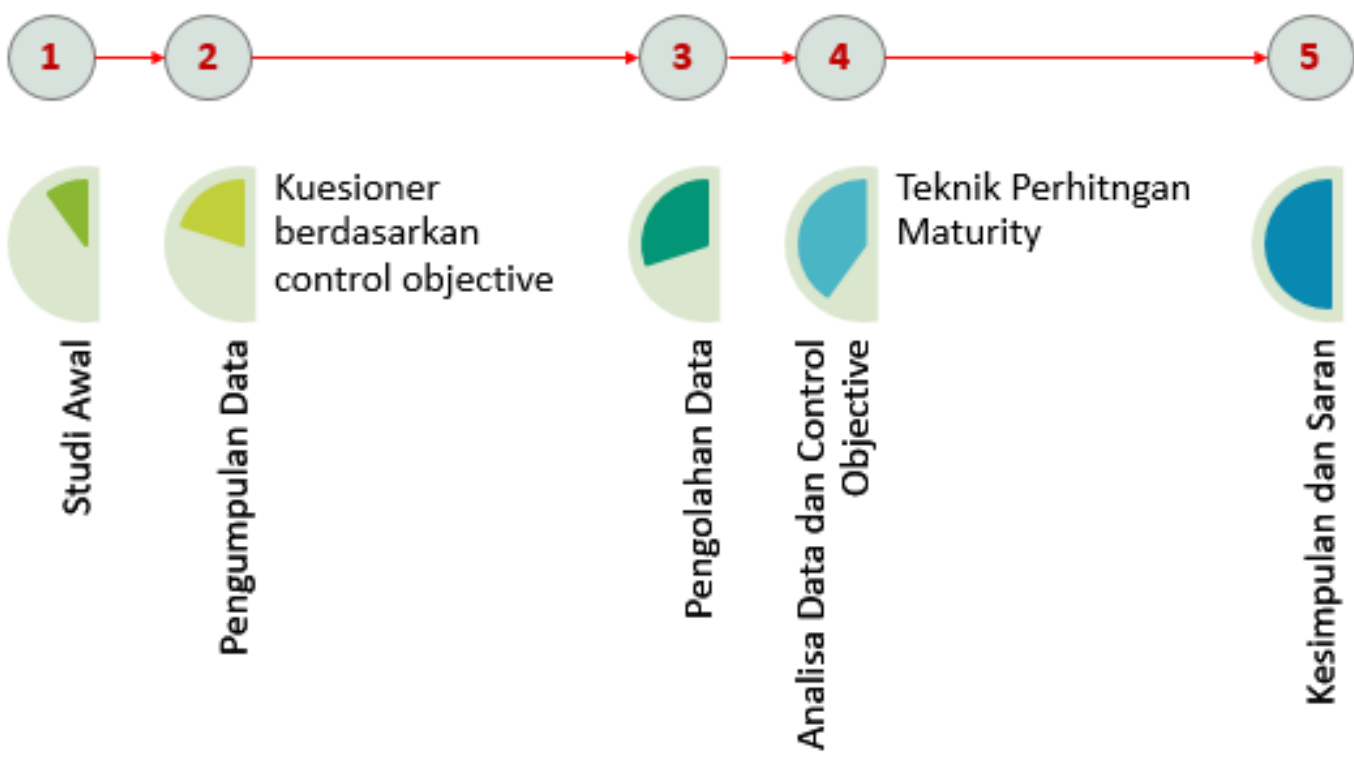

Langkah pertama penelitian ini diawali dengan melakukan studi awal dan analisis. Analisis merupakan suatu kegiatan berfikir untuk menguraikan suatu keseluruhan menjadi komponen sehingga dapat mengenal tanda-tanda dari setiap komponen, hubungan satu sama lain dan fungsi masing-masing dalam suatu keseluruhan yang terpadu. [14]

Penelitian ini dilakukan pada PTIPD UIN Walisongo Semarang, Pusat Teknologi Informasi dan Pangkalan Data mempunyai tugas mengelola dan mengembangkan sistem informasi di lingkungan Institusi. PTIPD dipimpin oleh seorang Kepala yang diangkat oleh Rektor, berada di bawah dan bertanggung jawab kepada Wakil Rektor Bidang Administrasi Umum, Perencanaan dan Keuangan. [15]

Pada TeSCA perguruan tinggi akan ditinjau dari 5 kriteria yaitu :[9]

1. Kriteria 1 : Tata Kelola TIK PT, meliputi organisai, perencanaan dan evaluasi

2. Kriteria 2 : Infrastruktur dan Fasilitas TIK PT

3. Kriteria 3 : Sistem dan Aplikasi TIK PT

4. Kriteria 4 : Informasi dan Konten TIK PT

5. Kriteria 5 : Stakeholder TIK PT

Setelah itu, akan dilakukan pengisian instrumen self assesment oleh pejabat dan staff IT yang terlibat langsung. Pengisian instrumen self assesment disesuaikan dengan job description personil IT perguruan tinggi, menyesuaikan dengan kriteria yang ada. Kemudian selanjutnya dilakukan penghitungan scoring.

Selanjutnya dilakukan penghitungan scoring atau nilai Sub-Total per kriteria dengan rumus sebagai berikut :

\begin{tabular}{|l|l|}
\hline $\mathbf{K} \mathbf{1}=$ Subtotall $/ \mathbf{5 6} * \mathbf{1 0 0}$ & Nilai Tata Kelola dan Manajemen \\
$\mathbf{K} \mathbf{2}=$ Subtotall $/ \mathbf{7 1} * \mathbf{1 0 0}$ & Nilai Infrastruktur dan Fasilitas \\
$\mathbf{K} \mathbf{3}=$ Subtotall $/ \mathbf{4 6} * \mathbf{1 0 0}$ & Nilai Sistem Aplikasi \\
$\mathbf{K} \mathbf{4}=$ Subtotall $/ \mathbf{3 6} * \mathbf{1 0 0}$ & Nilai Konten dan Database \\
$\mathbf{K 5}=$ Subtotall $/ \mathbf{2 9} * \mathbf{1 0 0}$ & Nilai Sumber Daya Manusia \\
\hline
\end{tabular}


JSAI : Journal Scientific and Applied Informatics

Vol. 3, No. 3, November 2020, hal. 122-128

E-ISSN: 2614-3054; P-ISSN: 2614-3062, accredited by Kemenristekdikti, Sinta 5

DOI: 10.36085

Setelah nilai sub-total per kriteria diketahui kemudian dilakuakan penghitungan nilai total akhir dengan perhitungan score sebagai berikut :

$$
\mathrm{SCORE}=\mathrm{K} 1 * 0.25+\mathrm{K} 2 * 0.15+\mathrm{K} 3 * 0.20+\mathrm{K} 4 * 0.15+\mathrm{K5} * 0.25
$$

Langkah terakhir yaitu dengan dengan mengartikan nilai akhir. Dengan melihat nilai akhir yang dihasilkan, maka dapat diambil sejumlah kesimpulan mengenai seberapa besar sebuah perguruan tinggi telah melakukan adopsi penuh terhadap TIK dalam konteks menuju implementasi paradigma pendidikan abad ke-21. Sebelum menggolongkan institusi terkait berdasarkan tingkat adopsi yang dimaksud, perlu dilihat terlebih dahulu arti dari masing-masing sub-total nilai per kriteria sebagai mana terlihat dalam tabel berikut ini.[9]

\begin{tabular}{|c|c|c|c|c|c|}
\hline & $\begin{array}{l}\text { SCORE } \\
<20.00 \\
\end{array}$ & $\begin{array}{c}\text { SCORE } \\
20.00-39.99 \\
\end{array}$ & $\begin{array}{c}\text { SCORE } \\
40.00-59.99 \\
\end{array}$ & \begin{tabular}{|c|} 
SCORE \\
$60.00-79.99$ \\
\end{tabular} & $\begin{array}{c}\begin{array}{c}\text { SCORE } \\
>=80\end{array} \\
\end{array}$ \\
\hline $\begin{array}{c}\text { Kriteria } \\
1\end{array}$ & $\begin{array}{c}\text { Manajemen } \\
\text { Ad-Hoc }\end{array}$ & $\begin{array}{c}\text { Manajemen } \\
\text { Berpola }\end{array}$ & $\begin{array}{l}\text { Manajemen } \\
\text { Standar }\end{array}$ & $\begin{array}{l}\text { Manajemen } \\
\text { Mahir }\end{array}$ & $\begin{array}{c}\text { Manajemen } \\
\text { Best Practice }\end{array}$ \\
\hline $\begin{array}{c}\text { Kriteria } \\
2\end{array}$ & $\begin{array}{c}\text { Infrastruktur } \\
\text { Ad-Hoc }\end{array}$ & $\begin{array}{c}\text { Infrastruktur } \\
\text { Minimal }\end{array}$ & $\begin{array}{l}\text { Infrastruktur } \\
\text { Standar }\end{array}$ & $\begin{array}{c}\text { Infrastruktur } \\
\text { Moderen }\end{array}$ & $\begin{array}{c}\text { Infrastruktur } \\
\text { Mutakhir }\end{array}$ \\
\hline $\begin{array}{c}\text { Kriteria } \\
3\end{array}$ & $\begin{array}{c}\text { Aplikasi } \\
\text { Minimalis }\end{array}$ & $\begin{array}{l}\text { Aplikasi } \\
\text { Sporadis }\end{array}$ & $\begin{array}{l}\text { Aplikasi } \\
\text { Standar }\end{array}$ & $\begin{array}{c}\text { Aplikasi } \\
\text { Tersistem }\end{array}$ & $\begin{array}{c}\text { Aplikasi } \\
\text { Terintegrasi }\end{array}$ \\
\hline $\begin{array}{c}\text { Kriteria } \\
4\end{array}$ & $\begin{array}{c}\text { Konten } \\
\text { Minimalis }\end{array}$ & $\begin{array}{c}\text { Konten } \\
\text { Sporadis }\end{array}$ & $\begin{array}{c}\text { Konten } \\
\text { Terstruktur }\end{array}$ & $\begin{array}{c}\text { Konten } \\
\text { Tersistem }\end{array}$ & $\begin{array}{c}\text { Konten } \\
\text { Terintegrasi }\end{array}$ \\
\hline $\begin{array}{c}\text { Kriteria } \\
\mathbf{5}\end{array}$ & $\begin{array}{c}\text { SDM } \\
\text { Terbatas }\end{array}$ & SDM Cukup & SDM Mahir & SDM Unggul & SDM Inovatif \\
\hline
\end{tabular}

\section{HASIL DAN ANALISIS}

Didalam Tesca secara garis besar terdapat lima Kriteria Penilaian Tingkat Kematangan TIK perguruan tinggi yaitu yang pertama tata kelola teknologi informasi komunikasi perguruan tinggi. Kriteria kedua infrastruktur dan fasilitas TIK perguruan tinggi. Ketiga sistem dan aplikasi TIK perguruan tinggi. Keempat informasi dan konten TIK perguruan tinggi. Kelima Stakeholder TIK perguruan tinggi.

Dari hasil penelitian yang telah dilakukan, yaitu dengan melakukan penghitungan scoring dan analisis GAP diperoleh sesuai dengan tabel berikut

\begin{tabular}{llrrr} 
No & \multicolumn{1}{c}{ Kriteria } & Score & Ideal & GAP \\
\hline K1 & Tata Kelola TIK & 50 & 80 & 30 \\
K2 & Infrastruktur dan Fasilitas TIK & 74,65 & 80 & 5,352 \\
K3 & Sistem dan Aplikasi TIK & 56,52 & 80 & 23,48 \\
K4 & Informasi dan Konten TIK & 50 & 80 & 30 \\
K5 & Stakeholder TIK & 51,72 & 80 & 28,28
\end{tabular}


JSAI : Journal Scientific and Applied Informatics

Vol. 3, No. 3, November 2020, hal. 122-128

E-ISSN: 2614-3054; P-ISSN: 2614-3062, accredited by Kemenristekdikti, Sinta 5

DOI: 10.36085

Dari tabel tersebut diatas dapat di ilustrasikan dengan grafik jaring laba-laba. Dari grafik terlihat jelas bahwa kriteria infrastruktur menunjukkan nilai yang tertinggi.

\section{TINGKAT KEMATANGAN PEMANFAATAN TIK PT}

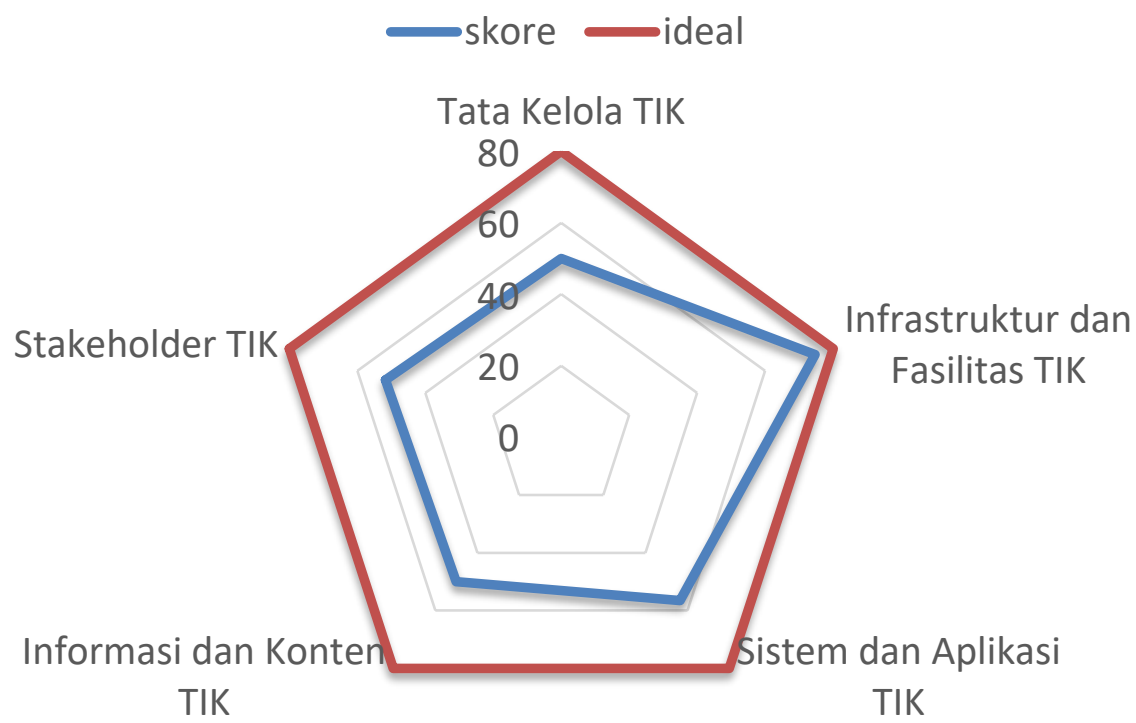

Dari grafik dan tabel diatas dapat diketahui bahwa evaluas TIK di UIN Walisongo nilai tertinggi pada kriteria 2 (dua) yaitu pada infrastruktun dan fasilitas TIK dengan nilai sebesar 74,65. Mempunyai nilai GAP sebesar 5,35. Selanjutnya kriteria 3 yaitu Sistem dan aplikasi TIK dengan score nilai sebesar 56,52. Mempunyai nilai GAP 23,48. Sedangkan kriteria 5 (lima) yaitu pada stakeholder TIK dengan nilai sebesar 51,72. Mempunya nilai GAP 28,28. Kemudian untuk kriteria 1 (satu) yaitu tata kelola TIK dan kriteria 4 (empat) yaitu informasi dan konten, masing-masing mempunyai skore 50 dengan masing-masing GAP 30.

\begin{tabular}{|c|c|c|c|c|c|}
\hline & $\begin{array}{l}\text { SCORE } \\
<20.00\end{array}$ & $\begin{array}{c}\text { SCORE } \\
20.00-39.99\end{array}$ & $\begin{array}{c}\text { SCORE } \\
40.00-59.99\end{array}$ & $\begin{array}{c}\text { SCORE } \\
60.00-79.99\end{array}$ & $\begin{array}{l}\text { SCORE } \\
>=80\end{array}$ \\
\hline $\begin{array}{c}\text { Kriteria } \\
1\end{array}$ & $\begin{array}{l}\text { Manajemen } \\
\text { Ad-Hoc }\end{array}$ & $\begin{array}{c}\text { Manajemen } \\
\text { Berpola }\end{array}$ & $\begin{array}{l}\text { Manajemen } \\
\text { Standar }\end{array}$ & $\begin{array}{l}\text { Manajemen } \\
\text { Mahir }\end{array}$ & $\begin{array}{l}\text { Manajemen } \\
\text { Best Practice }\end{array}$ \\
\hline $\begin{array}{c}\text { Kriteria } \\
2\end{array}$ & $\begin{array}{c}\text { Infrastruktur } \\
\text { Ad-Hoc }\end{array}$ & $\begin{array}{l}\text { Infrastruktur } \\
\text { Minimal }\end{array}$ & $\begin{array}{c}\text { Infrastruktur } \\
\text { Standar }\end{array}$ & $\begin{array}{c}\text { Infrastruktur } \\
\text { Moderen }\end{array}$ & $\begin{array}{l}\text { nfrastruktur } \\
\text { Mutakhir }\end{array}$ \\
\hline $\begin{array}{c}\text { Kriteria } \\
\mathbf{3}\end{array}$ & $\begin{array}{c}\text { Aplikasi } \\
\text { Minimalis }\end{array}$ & $\begin{array}{l}\text { Aplikasi } \\
\text { Sporadis }\end{array}$ & $\begin{array}{l}\text { Aplikasi } \\
\text { Standar }\end{array}$ & $\begin{array}{c}\text { Aplikasi } \\
\text { Tersistem }\end{array}$ & $\begin{array}{c}\text { Aplikasi } \\
\text { Terintegrasi }\end{array}$ \\
\hline $\begin{array}{c}\text { Kriteria } \\
4\end{array}$ & $\begin{array}{c}\text { Konten } \\
\text { Minimalis }\end{array}$ & $\begin{array}{l}\text { Konten } \\
\text { Sporadis }\end{array}$ & $\begin{array}{c}\text { Konten } \\
\text { Terstruktur }\end{array}$ & $\begin{array}{c}\text { Konten } \\
\text { Tersistem }\end{array}$ & $\begin{array}{c}\text { Konten } \\
\text { Terintegrasi }\end{array}$ \\
\hline $\begin{array}{c}\text { Kriteria } \\
\mathbf{5}\end{array}$ & $\begin{array}{c}\text { SDM } \\
\text { Terbatas }\end{array}$ & SDM Cukup & SDM Mahir & SDM Unggul & SDM Inovatif \\
\hline
\end{tabular}

Setelah diketahui nilai skore masing-masing kriteria langkah selanjutnya adalah melakukan koversi penamaan berdasarkan skore yang didapat masing-masing kriteria mengacu pada tabel penamaan TeSCA. Dari skore dan tabel tersebut dapat diketahui bahawa evaluasi tata kelola TIK pada UIN Walisongo menunjukkan bahwa pada manajemen tata kelola TIK pada manajemen 
standart, infrastruktur dan fasilitas TIK pada infrastruktur modern, sistem dan aplikasi TIK pada aplikasi standar, informasi dan konten TIK pada konten terstruktur dan stakeholder pada tingkat SDM mahir.

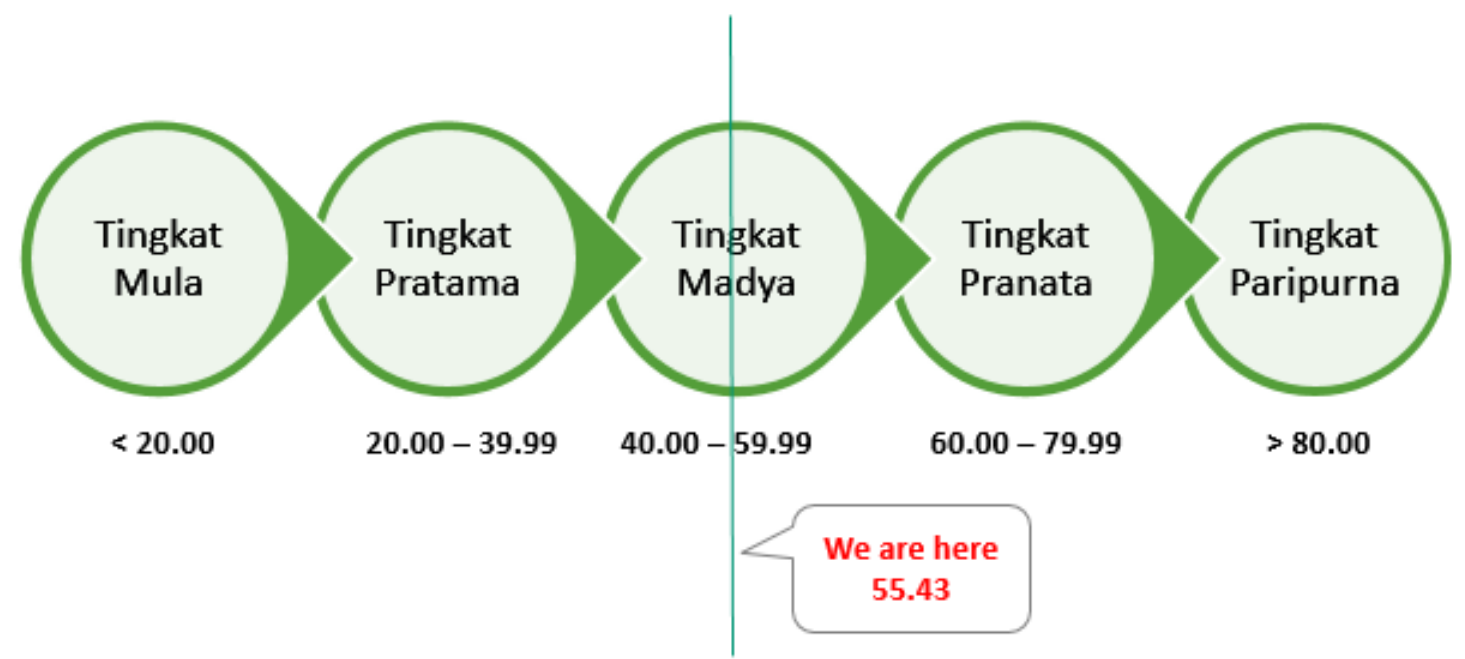

Selanjutnya setelah diketahui skore masing-masing kriteria, kemudian dilakukan integrasi skoring akhir. Dengan menggunakan rumus dan acuan yang telah ditetapkan metode TeSCA. Dari intergrasi tersebut diketahuai pada UIN Walisongo pada skore 55.43 dengan tata kelola TIK pada tingkat Madya.

\section{KESIMPULAN}

Metode TeSCA dapat dipakai dalam evaluasi tingkat kematangan TIK pada perguruan tinggi. Metode TeSCA cukup sederhana untuk melakukan self assement tingkat kematangan TIK perguruan tinggi. Metode TeSCA dapat digunakan sebagai indikator awal dalam melakukan evaluasi TIK. Dari hasil penelitian diketahui bahwa tingkat kematangan pemanfaatan TIK di di UIN Walisongo paling tinggi pada kriteria infrastruktur dan fasilitas TIK dengan nilai skore sebesar 74.65. Sedangkan Kriteria 1 pada tata kelola TIK dan Kriteria 4 pada Informasi dan Konten TIK nilai maturity nya sebesar 50. Untuk, Kriteria 3 pada sistem dan aplikasi TIK didapat nilai skor 56.52. Sedangkan K5 pada stakeholder TIK didapat nilai skor 51,72. Yang artinya pada kriteria tata kelola dan manajemen berada pada tahap manajemen standar, kriteria infrastrukur dan fasilitas pada tahap infrastruktur modern. Sedangkan kriteria system aplikasi pada tahap aplikasi standar, kriteria sumber daya manusia 5 pada tingkat SDM mahir. Jika di akumulasi maka skore tingkat kematangan TIK di UIN Walisongo dengan metode TEsCA pada tingkat level madya dengan skore total 55.43.

\section{UCAPAN TERIMA KASIH}

Terimakasih kepada seluruh jajaran staff PTIPD yang telah membantu dan memberi akses sehingga penelitian ini dapat berjalan dengan lancar.

\section{REFERENSI}

[1] M. Megawati and F. Amrullah, "Evaluasi Tingkat Kematangan Teknologi Informasi Dengan Menggunakan Model Maturity Level Cobit 4.1 (Studi Kasus Pt. Bri Cabang Bangkinang)," J. Sains dan Teknol. Ind., vol. 12, no. 1, pp. 99-105, 2014.

[2] D. Applegate, L. Austin, R. D., \& Soule and L., Corporate Information Strategy and Management 8th Edition. New York: Mc Graw Hill., 2009.

[3] O. G. Hekhmatyar and D. Supriyadi, "Measurement Satisfaction Information System Quality Service On BSI Using Webqual And CSI," Indones. J. onComputer Inf. Technol., vol. 2, no. 
2, pp. 1-6, 2017.

[4] A. Arliyana, "Analisa Tingkat Kematangan Tata Kelola Sistem Teknologi Informasi dan Komunikasi (Studi Kasus : UPT Perpustakaan STMIK Palangkaraya)," J. SAINTEKOM, vol. 8, no. 1, p. 52, 2018.

[5] Mk. Teknik Komputer, S. Tinggi Teknologi Payakumbuh, D. Teknik Komputer, and R. Irsa Teknik Komputer, "Pemetaan Dan Pengukuran Pemanfaatan TIK Menggunakan Metode Echosystem (Studi Kasus STT-Payakumbuh)," Elkawnie J. Islam. Sci. Technol., vol. 1, no. $1,2016$.

[6] S. Tetiaavini, "EVALUASI PEMANFAATAN TATA KELOLA TEKNOLOGI INFORMASI DAN KOMUNIKASI (TIK) PADA PENERAPAN E-KTP MENGGUNAKAN FRAMEWORK COBIT," J. Inform. Glob. Vol., vol. 53, no. 9, pp. 16891699, 2012.

[7] A. Fattah, "Evaluasi Tata Kelola Teknologi Informasi (Ti) Berbasis Tesca Pada Universitas Balikpapan," JTT (Jurnal Teknol. Terpadu), vol. 7, no. 1, pp. 10-16, 2019.

[8] S. Gondodiyoto, Audit Sistem Informasi+Pendekatan CobIT. Jakarta: Mitra Wacana Media, 2007.

[9] R. Eko Indrajit, Teknologi Informasi dan Perguruan Tinggi: Mejawab Tantangan Pendidikan Abad ke-21. 2011.

[10] W. Jogiyanto \& Abdillah, Sistem Tatakelola Teknologi Informasi. Yogyakarta: Andi, 2011.

[11] A. Hanif, M. Giatman, and A. Hadi, "KOMUNIKASI DAN INFORMATIKA MENGGUNAKAN FRAMEWORK COBIT 5," vol. 9, no. 1, pp. 94-101, 2020.

[12] U. Walisongo, "Visi Misi UIN Walisongo," 2020. [Online]. Available: https://walisongo.ac.id/?page_id=4370.

[13] D. M. Masruroh, S. Sardjono, and A. Halik, "Pengaruh Harga, Sosial Media Marketing Dan Brand Equity Terhadap Customer Purchase Decision Melalui Consumer Respon Sebagai Variabel Intervening Pada Jamaah Umroh Pt Saraya Anugrah Di Sidoarjo,” J. Ekon. Bisnis, vol. 4, no. 2, pp. 987-1003, 2019.

[14] M. P. Islamiah, "Tata Kelola Teknologi Informasi (IT Governance) Menggunakan Framework COBIT 5," Skripsi. Jakarta. UIN Syarif Hidayatullah., vol. 5, pp. 561-565, 2014.

[15] PTIPD, "Pusat Teknologi Informasi dan Pangkalan Data." [Online]. Available: http://ptipd.walisongo.ac.id/. [Accessed: 25-Nov-2020]. 